\title{
Renal Association Clinical Practice Guideline on Peritoneal Dialysis
}

\author{
Dr Graham Woodrow ${ }^{a}$ and Professor Simon Davies ${ }^{b}$ \\ ${ }^{a}$ Consultant Nephrologist, Leeds Teaching Hospitals NHS Trust \\ ${ }^{b}$ Consultant Nephrologist, University Hospital of North Staffordshire, Stoke-on-Trent
}

\section{Key Words}

Peritoneal dialysis $\cdot$ peritonitis $\cdot$ solute clearance $\cdot$ ultrafiltration - metabolic complications - encapsulating peritoneal sclerosis

\section{Introduction}

Peritoneal dialysis (PD) is long established as a major option for renal replacement therapy in patients with end-stage renal disease. It is an important part of an integrated service for renal replacement therapy that is frequently selected by patients as their preferred initial mode of therapy and is a therapeutic option for patients wishing or needing to swap from HD and after renal transplant failure.

This guideline is an update of the PD module published on-line on the Renal Association website, www.renal.org in 2007. The English language literature was searched to identify relevant articles on PD published between 2006 and 2010 including:

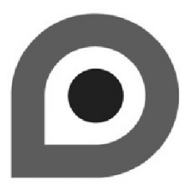

NHS Evidence Accreditation Mark
- Medline search using 'peritoneal dialysis' combined with relevant terms

- Cochrane Database of Systematic Reviews

- Review of other national/international PD clinical guidelines

- Identification of further articles quoted in identified papers

The recommendations in this version of the Renal Association Clinical Practice Guidelines for Peritoneal Dialysis guideline have been assessed according to the modified GRADE system. The system was produced by a group of guideline developers and experts in evidence-based medicine. It explicitly describes both the strength of the recommendations and the quality of the underlying evidence, with the aim of maximising applicability to standard clinical practice [1-6]. The system grades level of expert recommendation as 'strong' (Grade 1) or 'weak' (Grade 2) according to balance of benefits, risk, burden and cost. The quality or level of evidence is assessed as 'high' (Grade A), 'moderate' (Grade B), 'low' (Grade C) or 'very low' (D) depending

\section{KARGER}

Fax +41613061234 E-Mail karger@karger.ch www.karger.com
C 2011 S. Karger AG, Basel

$1160-2110 / 11 / 1185-000287 \$ 38.00 / 0$
Dr Graham Woodrow and Professor Simon Davies

Email: Graham.Woodrow@leedsth.nhs.uk or simondavies1@compuserve.com 
on factors such as study design, directness of evidence and consistency of results. The modified GRADE system has been adopted by the Renal Association Clinical Practice Guidelines Committee and is widely used by a large number of clinical guideline organisations including NICE, SIGN, KDIGO, ERBP, KDOQI, BMJ and WHO $[4,7,8]$. The recommendations in this guideline have been harmonised with other PD guidelines whenever possible and the recommendations to follow international PD guidelines have not been graded. The Renal Association has produced a separate clinical practice guideline for PD catheter insertion which has been adopted by the International Society of Peritoneal Dialysis, has been published elsewhere [9] and is available on the Renal Association website www.renal. org/Clinical/GuidelinesSection/PeritonealAccess.aspx

\section{References}

1 Atkins D, Best D, Briss PA et al. Grading quality of evidence and strength of recommendations. BMJ 2004;328:1490

- 2 Guyatt G, Gutterman D, Baumann MH et al. Grading strength of recommendations and quality of evidence in clinical guidelines. Chest 2006;129:174-181

3 Guyatt GH, Oxman AD, Vist GE et al. GRADE: an emerging consensus on rating quality of evidence and strength of recommendations. BMJ 2008;336:924-926

4 Guyatt GH, Oxman AD, Kunz R et al. GRADE: going from evidence to recommendations. BMJ 2008;336:1049-1051

$\checkmark 5$ Guyatt GH, Oxman AD, Kunz R et al. GRADE: Incorporating considerations of resources use into grading recommendations. BMJ 2008;336:1170-1173
6 Jaeschke R, Guyatt GH, Dellinger P et al. Use of GRADE grid to reach decisions on clinical practice guidelines when consensus is elusive. BMJ 2008;337:327-330

7 Uhlig K, MacLeod A, Craig J et al. Grading evidence and recommendations for clinical practice guidelines in nephrology. A position statement from Kidney Disease: Improving Global Outcomes (KDIGO). Kidney Int 2006;70:2058-2065

$\checkmark 8$ Kidney Disease: Improving Global Outcomes. KDIGO clinical practice guidelines for the prevention, diagnosis, evaluation and treatment of Hepatitis C in chronic kidney disease. Kidney Int 2008;73(S109):S1-99

9 Figueiredo A, Goh B, Jenkins S, Johnson DW, Mactier R, Ramalakshmi S, Shrestha B, Struijk D, Wilkie M. Clinical practice guidelines for peritoneal access. Perit Dial Int 2010;30:424-429 


\section{Summary of Clinical Practice Guidelines on Peritoneal Dialysis}

\section{Peritoneal Dialysis (PD) (Guidelines PD 1.1-1.5)}

\section{Guideline 1.1 - PD: Equipment and Resources}

Guideline 1.1.1 - PD: Resources

We recommend that Peritoneal Dialysis should be delivered in the context of a comprehensive and integrated service for renal replacement therapies, including haemodialysis (including temporary backup facilities), transplantation and conservative care. Both continuous ambulatory peritoneal dialysis (CAPD) and automated peritoneal dialysis (APD), in all its forms should be available. (1C)

\section{Guideline 1.1.2 - PD: Resources}

We recommend that dedicated PD nursing staff (1 W.T.E. per 20 patients) should be part of the multidisciplinary team. (1C)

\section{Guideline 1.1.3 - PD: Resources}

We recommend that each unit has a designated lead clinician for PD. (1C)

\section{Guideline 1.1.4 - PD: Resources}

We recommend that assisted PD should be available to patients wishing to have home dialysis treatment but unable to perform self-care PD. (1C)

\section{Guideline 1.2 - PD: Equipment and Resources}

We recommend that all equipment used in the delivery and monitoring of therapies should comply with the relevant standards for medical electrical equipment [BS-EN 60601-2-39:1999, BS5724-2-39:1998, IEC 60601-2-39:1998, Particular requirements for the safety - specification for peritoneal dialysis equipment]. Tubing sets and catheters should carry the 'CE' mark to indicate that the item conforms to the essential requirements of the Medical Devices Directive (93/42/ EEC) and that its conformity has been assessed in accordance with the directive. (1C)

\section{Guideline 1.3 - PD: Equipment and Resources}

We recommend that fluids for peritoneal dialysis are required to satisfy the current European quality standards as indicated in the European good manufacturing practice and the European Pharmacopoeia Monograph 'Solutions for Peritoneal Dialysis'. Manufacturing facilities are required to meet the relevant standards (ISO
9001/2 and EN 46001/2). Product registration files must be submitted to and product approval given by the Medicines Control Agency. (1C)

\section{Guideline 1.4 - PD: Equipment and Resources}

We recommend that the use of disconnect systems should be standard unless clinically contraindicated. (1A)

\section{Guideline 1.5 - PD: Equipment and Resources}

We suggest that biocompatible PD solutions (normal $\mathrm{pH}$, low concentrations of glucose degradation products) should be used in patients experiencing infusion pain. (2B)

\section{Peritoneal Dialysis (PD) (Guidelines PD 2.1-2.4)}

\section{Guideline 2.1 - PD: Preparation for Peritoneal Dialysis}

We recommend that all patients should, where possible, be adequately prepared for renal replacement therapy and this should include receiving information and education about PD treatment, delivered by an experienced member of the MDT. Patients commencing RRT in an unplanned fashion for whatever reason should receive this information once appropriate. (1C) Fast track education and urgent PD catheter insertion with acute start of PD should be available, and be offered to suitable patients urgently starting on RRT who wish to avoid temporary haemodialysis. (1C)

\section{Guideline 2.2 - PD: Preparation for Peritoneal Dialysis}

We recommend that, where possible, timing of PD catheter insertion should be planned to accommodate patient convenience, and commencement of training between 10 days and 6 weeks before RRT is essential to enable correction of early catheter-related problems without the need for temporary haemodialysis. (1C)

\section{Guideline 2.3 - PD: Preparation for Peritoneal Dialysis}

We recommend that $\mathrm{PD}$ catheter insertion practice should be managed according to the Renal Association Peritoneal Access Guidelines.

\section{Guideline 2.4 - PD: Preparation for Peritoneal Dialysis}

We recommend that peri-operative catheter care and catheter complications (leaks, hernias, obstruction) should be managed according to the International Society of Peritoneal Dialysis guidelines. 
3. Peritoneal Dialysis (PD) (Guidelines PD 3.1-3.3)

\section{Guideline 3.1 - PD: Solute Clearance}

We recommend that both residual urine and peritoneal dialysis components of small solute clearance should be measured at least six monthly or more frequently if dependant on residual renal function to achieve clearance targets or if clinically or biochemically indicated. Both urea and/or creatinine clearances can be used to monitor dialysis adequacy and should be interpreted within the limits of the methods. (1C)

\section{Guideline 3.2.1 - PD: Solute Clearance}

We recommend that a combined urinary and peritoneal $\mathrm{Kt} / \mathrm{V}_{\text {urea }}$ of $1.7 /$ week or a creatinine clearance of $50 \mathrm{~L} /$ week $/ 1.73 \mathrm{~m}^{2}$ should be considered as minimal treatment doses. (1A)

\section{Guideline 3.2.2 - PD: Solute Clearance}

We recommend that the dose should be increased in patients experiencing uraemic symptoms. (1B)

\section{Guideline 3.3 - PD: Solute Clearance}

We recommend that a continuous 24 hour PD regime is preferred to an intermittent regime. (1B)

\section{Peritoneal Dialysis (PD) (Guidelines PD 4.1-4.5)}

\section{Guideline 4.1 - PD: Ultrafiltration and Fluid Management}

We recommend that peritoneal membrane function should be monitored regularly (6 weeks after commencing treatment and at least annually or when clinically indicated) using a peritoneal equilibration test (PET) or equivalent. Daily urine and peritoneal ultrafiltration volumes, with appropriate correction for overfill, should be monitored at least six-monthly. (1C)

\section{Guideline 4.2 - PD: Ultrafiltration and Fluid Management}

We recommend that dialysis regimens resulting in fluid reabsorption should be avoided. Patients with high or high average solute transport, at greatest risk of this problem, should be considered for APD and icodextrin. (1A)

\section{Guideline 4.3 - PD: Ultrafiltration and Fluid Management}

We recommend that dialysis regimens resulting in routine utilisation of hypertonic (3.86\%) glucose exchanges should be avoided. Where appropriate this should be achieved by using icodextrin or diuretics. (1B)

\section{Guideline 4.4 - PD: Ultrafiltration and Fluid Management}

We recommend that treatment strategies that favour preservation of renal function should be adopted where possible. These include the use of ACEi, ARBs and diuretics, and the avoidance of episodes of dehydration. (1B)

\section{Guideline 4.5 - PD: Ultrafiltration and Fluid Management}

We recommend that anuric patients who consistently achieve a daily ultrafiltration of less than $750 \mathrm{ml}$ should be closely monitored and the benefits of modality switch considered. (1B)

\section{Peritoneal Dialysis (PD) (Guidelines PD 5.1-5.2)}

\section{Guideline 5.1 - PD: Infectious Complications}

Guideline 5.1.1 - PD Infectious Complications:

\section{Prevention Strategies}

We recommend that PD units should undertake regular audit of their peritonitis and exit-site infection rates, including causative organism, treatment and outcomes. They should enter into active dialogue with their microbiology department and infection control team to develop optimal local treatment and prevention protocols. (1B)

\section{Guideline 5.1.2 - PD Infectious Complications: Prevention Strategies}

We recommend that flush-before-fill dialysis delivery systems should be used. (1A)

\section{Guideline 5.1.3 - PD Infectious Complications: Prevention Strategies}

We recommend that patients should undergo regular revision of their technique (at least annually or more frequently if indicated, such as after an episode of PDrelated infection or a significant interruption to the patient performing PD) and receive intensified training if this is below standard. (1C)

\section{Guideline 5.1.4 - PD Infectious Complications: Prevention Strategies}

We recommend that initial catheter insertion should be accompanied by antibiotic prophylaxis. (1B) 
Guideline 5.1.5 - PD Infectious Complications: Prevention Strategies

We recommend that invasive procedures should be accompanied by antibiotic prophylaxis and emptying the abdomen of dialysis fluid for a period commensurate with the procedure. (1C)

\section{Guideline 5.1.6 - PD Infectious Complications:} Prevention Strategies

We recommend that topical antibiotic administration should be used to reduce the frequency of Staph. aureus and Gram negative exit-site infection and peritonitis. (1A)

\section{Guideline 5.2 - PD Infectious Complications Guideline 5.2.1 - PD Infectious Complications: Treatment}

We recommend that exit site infection is suggested by pain, swelling, crusting, erythema and serous discharge; purulent discharge always indicates infection. Swabs should be taken for culture and initial empiric therapy should be with oral antibiotics that will cover $S$. aureus and $P$. aeruginosa. (1B)

\section{Guideline 5.2.2 - PD Infectious Complications: Treatment}

We recommend that methicillin resistant organisms (MRSA) will require systemic treatment (e.g. vancomycin) and will need to comply with local infection control policies. (1C)

\section{Guideline 5.2.3 - PD Infectious Complications: Treatment}

We recommend that initial treatment regimens for peritonitis should include cover for bacterial Gram positive and Gram negative organisms including Pseudomonas species until result of culture and antibiotic sensitivities are obtained. (1C)

\section{Peritoneal Dialysis (PD) (Guidelines PD 6.1-6.4)}

\section{Guideline 6.1 - PD: Metabolic Factors}

We recommend that standard strategies to optimise diabetic control should be used; these should be complemented by dialysis prescription regimens that minimise glucose, including glucose free solutions (icodextrin and amino-acids), where possible. (1B)

\section{Guideline 6.2 - PD: Metabolic Factors}

We recommend that plasma bicarbonate should be maintained within the normal range; this can be achieved in the vast majority of patients by adjusting the dialysis dose and/or dialysate buffer concentration. Occasionally bicarbonate buffered solutions will be required. (1B)

\section{Guideline 6.3 - PD: Metabolic Factors}

We suggest that central obesity can worsen or develop in some PD patients. The risk of this problem, and associated metabolic complications, notably increased atherogenicity of lipid profiles and insulin resistance, can be reduced by avoiding excessive glucose prescription and using icodextrin. (2C)

\section{Guideline 6.4 - PD: Metabolic Factors}

We recommend that awareness of the effects of icodextrin on assays for estimation of amylase and glucose (using glucose dehydrogenase) should be disseminated to patients, relatives, laboratory and clinical staff. (1C)

\section{Peritoneal Dialysis (PD) (Guidelines PD 7.1)}

\section{Guideline 7.1 - PD: Encapsulating Peritoneal Sclerosis}

We recommend that the diagnosis and management of encapsulating peritoneal sclerosis (EPS), including consideration of surgical management of EPS, should follow the principles outlined in the UK Encapsulating Peritoneal Sclerosis Clinical Practice Guidelines. (not graded)

\section{Guideline 7.2 - PD: Encapsulating Peritoneal Sclerosis}

We recommend that there is no optimal duration of peritoneal dialysis and decisions regarding the duration of therapy should be tailored to the individual patient, taking into account clinical and social factors and patients wishes, and should follow the principles outlined in the ISPD Length of Time on Peritoneal Dialysis and Encapsulating Peritoneal Sclerosis Position Paper. (not graded) 


\section{Summary of Audit Measures for Peritoneal Dialysis}

1. Availability of modality choice

2. Monitoring of modality switching

3. Patient to peritoneal dialysis nursing staff ratio

4. Availability of assisted PD, utilisation and outcomes

5. Systems in place to check medical equipment

6. Systems in place to ensure purchase of dialysis fluid fulfil legal requirements

7. Use of non-standard systems with documentation of clinical indication

8. Use of biocompatible solutions and indication for use

9. Audit of care pathway for dialysis preparation to include information given (including proportion of patients offered PD), when and who delivers it

10. Audit of information on modality options provided to patients presenting who urgently require RRT, and both initial and subsequent modality of RRT selected by these patients

11. Audit of care pathway for catheter insertion to include timeliness and need for temporary haemodialysis

12. Catheter complications and their resolution
13. Frequency of solute clearance (residual and peritoneal) estimation

14. Cumulative frequency curves for the total solute clearance

15. Frequency of measurement of membrane function, residual urine and peritoneal ultrafiltration volume

16. Identify patients with fluid reabsorption in long dwell

17. Number of patients regularly requiring hypertonic $(3.86 \%$ glucose $)$ exchanges to maintain fluid balance

18. Identify patients with a total fluid removal $<750 \mathrm{ml}$ per day

19. Routine annual audit of infection prevention strategies

20. Routine annual audit of PD peritonitis rates (including proportion of culture negative cases)

21. Routine annual audit of infection outcomes

22. Cumulative frequency curves of plasma bicarbonate

23. Processes in place to increase awareness of interference of assays by icodextrin metabolites 


\section{Summary of Clinical Practice Guidelines for Peritoneal Dialysis}

\section{Peritoneal Dialysis (PD) (Guidelines PD 1.1-1.5)}

\section{Guideline 1.1 - PD: Equipment and Resources}

\section{Guideline 1.1.1 - PD: Resources}

We recommend that Peritoneal Dialysis should be delivered in the context of a comprehensive and integrated service for renal replacement therapies, including haemodialysis (including temporary backup facilities), transplantation and conservative care. Both continuous ambulatory peritoneal dialysis (CAPD) and automated peritoneal dialysis (APD), in all its forms should be available. (1C)

\section{Guideline 1.1.2 - PD: Resources}

We recommend that dedicated PD nursing staff (1 W.T.E. per 20 patients) should be part of the multidisciplinary team. (1C)

\section{Guideline 1.1.3 - PD: Resources}

We recommend that each unit has a designated lead clinician for PD. (1C)

\section{Guideline 1.1.4 - PD: Resources}

We recommend that assisted PD should be available to patients wishing to have home dialysis treatment but unable to perform self-care PD. (1C)

\section{Audit Measures}

Availability of modality choice

Monitoring of modality switching

Patient to peritoneal dialysis nursing staff ratio

Availability of assisted PD, utilisation and outcomes

\section{Rationale for 1.1.1-1.1.4}

Evidence from observational studies or registry data, with all its limitations, indicate that peritoneal dialysis (PD) used in the context of an integrated dialysis programme is associated with good clinical outcomes, certainly comparable to haemodialysis in the medium term (HD) [1-6]. The only randomised study (NECO$\mathrm{SAD}$ ), comparing $\mathrm{HD}$ to $\mathrm{PD}$ as a first treatment showed no differences in 2 year quality adjusted life years or 5 year mortality, but the number randomised was insufficient to generalise this observation; notably, most patients in this national study had sufficient life-style preferences related to one modality to decline randomisation [7]. PD has a significant technique failure rate however, so patients need to be able to switch treatment modality (to either temporary or permanent HD) in a timely manner, which has implications for HD capacity.

PD modalities (CAPD v. APD) have a different impact on life-style; one randomised study found that APD creates more time for the patient to spend with family or continue employment but is associated with reduced quality of sleep [8]. APD is the preferred modality for children. There are medical indications for APD (see sections 2, 3 and 4), but generally modality choice is a lifestyle issue. Studies suggest no difference in outcomes resulting from selection of CAPD or APD as initial PD modality [9-11].

The success of a PD programme is dependent upon specialised nurses with appropriate skills in assessing and training patients for $\mathrm{PD}$, monitoring of treatment and with sufficient resources to provide continued care in the community. A recent randomised trial of more intensive training has shown that this reduces peritonitis risk [12] (see section 5). Several studies have documented the benefits of home visits in identifying new problems, reducing peritonitis and non-compliance [13-15]. It is usually possible for a WTE PD nurse to deliver this quality of care with a caseload of $20 \mathrm{PD}$ patients (see recommendations of the National Renal Workforce Planning Group, 2002). Having a designated lead clinician for PD in each unit may help to promote $\mathrm{PD}$ as a therapy option and to develop clinical management policy.

Assisted PD, with provision of nursing support in the community to help with part of the workload and procedures associated with $\mathrm{PD}$, is a useful option to overcome an important barrier to home dialysis therapy [16]. Assisted APD should be available for patients, who are often but not always elderly, wishing to have dialysis at home, but are unable to perform self-care PD.

\section{Guideline 1.2 - PD: Equipment and Resources}

We recommend that all equipment used in the delivery and monitoring of therapies should comply with the relevant standards for medical electrical equipment [BS-EN 60601-2-39:1999, BS5724-2-39:1998, IEC 60601-2-39:1998, Particular requirements for the safety - specification for peritoneal dialysis equipment]. Tubing sets and catheters should carry the 'CE' mark to indicate that the item conforms to the essential requirements of the Medical Devices Directive (93/42/ EEC) and that its conformity has been assessed in accordance with the directive. (1C) 


\section{Audit Measure}

Systems in place to check medical equipment

This is a legal requirement

\section{Guideline 1.3 - PD: Equipment and Resources}

We recommend that fluids for peritoneal dialysis are required to satisfy the current European quality standards as indicated in the European good manufacturing practice and the European Pharmacopoeia Monograph 'Solutions for Peritoneal Dialysis'. Manufacturing facilities are required to meet the relevant standards (ISO 9001/2 and EN 46001/2). Product registration files must be submitted to and product approval given by the Medicines Control Agency. (1C)

\section{Audit Measure}

Systems in place to ensure purchase of dialysis fluid fulfil legal requirements

This is a legal requirement

\section{Guideline 1.4 - PD: Equipment and Resources}

We recommend that the use of disconnect systems should be standard unless clinically contraindicated. (1A)

\section{Audit Measure}

Use of non-standard systems with documentation of clinical indication

\section{Rationale}

Disconnect systems have been shown through randomised trials to be associated with a lower peritonitis risk, especially in infections due to touch contamination [17].

\section{Guideline 1.5 - PD: Equipment and Resources}

We suggest that biocompatible PD solutions (normal $\mathrm{pH}$, low concentrations of glucose degradation products) should be used in patients experiencing infusion pain. (2B)

\section{Audit Measure}

Use of biocompatible solutions and indication for use

\section{Rationale}

A minority of patients commencing PD will experience infusion pain, often severe enough to consider discontinuing the therapy. A double blind randomised study demonstrated that pain could be prevented by using a normal $\mathrm{pH}$, bicarbonate-lactate buffered dialysis fluid (Physioneal) [18]. Subsequent clinical experience has found that the benefit of this more biocompatible solution on infusion pain results in immediate and sustained benefit, and is probably applicable to other biocompatible solutions.

The evidence of clinical benefit from the routine use of biocompatible solutions is more controversial. Standard solutions are clearly bio-incompatible, with low $\mathrm{pH}$ $(\sim 5.2)$, lactate rather than bicarbonate buffer, high osmolality and high concentrations of glucose which also result in high concentrations of glucose degradation products (GDPs). Many in vitro and ex vivo studies have demonstrated the relative toxicity of these solutions, with all of the bioincompatible features playing their part [1924]. There is also strong observational evidence that (a) detrimental functional changes to the peritoneal membrane occur with time on treatment, which are more exaggerated in patients using solutions with high glucose concentration early in their time on therapy $[25,26]$ and (b) morphological changes occur that are related to time on treatment which include membrane thickening and vascular scarring [27]. Time on treatment is also the greatest risk factor for encapsulating peritoneal sclerosis (EPS) $[28,29]$.

These observations have led all the main dialysis companies to develop and market 'biocompatible' solutions, with normalisation of $\mathrm{pH}$, reduction of GDPs and a variable approach to buffering. In randomised clinical trials these solutions have been shown to improve the dialysate concentrations of biomarkers considered to be indicators of mesothelial cell and possibly membrane health [30-33]. Systemic benefits possibly include reduced circulating advanced glycation end-products [33] and better glycaemic control in diabetics [34]. Data is currently lacking on hard clinical endpoints such as technique failure, functional membrane change or patient survival. One non-randomised, retrospective observational study has found an improved patient but not technique survival; patients in this study using biocompatible solutions were younger, suggesting a selection bias that may not be fully adjusted for, so caution should be exercised in the interpretation of this study [35]. Similar findings have been reported in a subsequent observational study, which has the advantage of including analysis of cohorts matched for factors including cardiovascular comorbidity, socioeconomic status and centre experience [36]. However, the limitations of being a non-randomised study with no fixed indication for prescription of biocompatible fluid, with potential for selection bias, and with differences in characteristics of the unmatched groups still apply [36]. Non-randomised, observational studies have also suggested a beneficial effect of biocompatible solutions 
on peritonitis rates $[37,38]$, but the strength of the conclusions are limited by the non-randomised study design and possibility of other factors contributing to observed differences in infection rates. Some studies have suggested a benefit of low-GDP biocompatible fluids on residual function [39]. However, confounding factors in these studies such as differences in ultrafiltration between groups (which may indirectly affect residual urine via effects on hydration) or cross-over study design, make conclusions on the actual effect of the fluids on residual renal function uncertain [40].

Currently there is insufficient evidence to recommend that all patients should be treated with biocompatible solutions, especially as this may have a significant cost implication. A selective approach to their use should be considered. Working on the assumption that the primary benefit of biocompatible solutions is membrane protection then there is evidence indicating that functional membrane changes become more significant at 4 years of treatment, even in patients commencing PD with good residual renal function and low use of hypertonic exchanges [26]. Likewise the incidence of EPS is rare before this period of time on treatment. This issue remains controversial at this stage and further studies are required.

\section{References}

1 Fenton SSA, Schaubel DE, Desmeules M, et al. Hemodialysis versus peritoneal dialysis: a comparison of adjusted mortality rates. American Journal of Kidney Diseases 1997;30(3):334-342

$\checkmark 2$ Vonesh EF, Snyder JJ, Foley RN, Collins AJ. The differential impact of risk factors on mortality in hemodialysis and peritoneal dialysis. Kidney Int 2004;66(6):2389-2401

-3 Heaf JG, Lokkegaard H, Madsen M. Initial survival advantage of peritoneal dialysis relative to haemodialysis. Nephrol Dial Transplant 2002;17(1):112-117

-4 Termorshuizen F, Korevaar JC, Dekker FW, Van Manen JG, Boeschoten EW, Krediet RT. Hemodialysis and peritoneal dialysis: comparison of adjusted mortality rates according to the duration of dialysis: analysis of the Netherlands cooperative study on the adequacy of dialysis 2 . J Am Soc Nephrol 2003;14(11):2851-2860

5 Collins AJ, Hao W, Xia H, et al. Mortality risks of peritoneal dialysis and hemodialysis. Am J Kidney Dis 1999;34(6):1065-1074

6 McDonald SP, Marshall MR, Johnson DW, Polkinghome KR. Relationship between dialysis modality and mortality. J Am Soc Nephrol 2009;20: 155-163

7 Korevaar JC, Feith GW, Dekker FW, et al. Effect of starting with hemodialysis compared with peritoneal dialysis in patients new on dialysis treatment: a randomised controlled trial. Kidney Int 2003;64(6): 2222-2228

$>8$ Bro S, Bjorner JB, Tofte-Jensen $\mathrm{P}$, et al. A prospective, randomised multicenter study comparing APD and CAPD treatment. Perit Dial Int 1999;19(6):526-533

$\checkmark 9$ Rabindranath KS, Adams J, Ali TZ, Daly C, Vale L, MacLeod AM. Automated vs continuous ambulatory peritoneal dialysis: a systematic review of randomised controlled trials. Nephrol Dial Transplant 2007;22:29912998

10 Michels WM, Verduijn M, Boeschoten EW, Dekker FW, Krediet RT. Similar survival on automated peritoneal dialysis and continuous ambulatory peritoneal dialysis in a large prospective cohort. Clin J Am Soc Nephrol 2009;4:943-949

$\checkmark 11$ Mehrotra R, Chiu Y-W, Kalantar-Zadeh K, Vonesh E. The outcomes of continuous ambulatory and automated peritoneal dialysis are similar. Kidney Int 2009;76:97-107

12 Hall G, Bogan A, Dreis S, et al. New directions in peritoneal dialysis patient training. Nephrol Nurs J 2004;31(2):149-154, 59-63

13 Lewis NM, Pickering KR. Establishment of a formalised CAPD retraining program. Perit Dial Int 1995;15:S58

14 Bernardini J, Piraino B. Compliance in CAPD and CCPD patients as measured by supply inventories during home visits. Am J Kidney Dis 1998;31(1):101-107
15 Ponferrada L, Prowant BF, Schmidt LM, Burrows LM, Satalowich RJ, Bartelt C. Home visit effectiveness for peritoneal dialysis patients. Anna J 1993;20(3):333-336

16 Povlsen JV, Ivarsen P. Assisted automated peritoneal dialysis (AAPD) for the functionally dependent and elderly patient. Perit Dial Int 2005; 25(Suppl 3):S60-63

17 MacLeod A, Grant A, Donaldson C, et al. Effectiveness and efficiency of methods of dialysis therapy for end-stage renal disease: systematic reviews. Health Technol Assess 1998;2(5):1-166

18 Mactier RA, Sprosen TS, Gokal R, et al. Bicarbonate and bicarbonate/ lactate peritoneal dialysis solutions for the treatment of infusion pain. Kidney Int 1998;53(4):1061-1067

19 Liberek T, Topley N, Jorres A, et al. Peritoneal dialysis fluid inhibition of polymorphonuclear leukocyte respiratory burst activation is related to the lowering of intracellular pH. Nephron 1993;65(2):260 265

20 Jorres A, Bender TO, Finn A, et al. Biocompatibility and buffers: effect of bicarbonate-buffered peritoneal dialysis fluids on peritoneal cell function. Kidney Int 1998;54(6):2184-2193

21 Jörres A, Topley N, Steenweg L, Müller C, Köttgen E, Gahl GM. Inhibition of cytokine synthesis by peritoneal dialysate persists throughout the CAPD cycle. Am J Nephrol 1992;12(1-2):80-85

22 McGregor SJ, Brock JH, Briggs JD, Junor BJ. Longitudinal study of peritoneal defence mechanisms in patients on continuous ambulatory peritoneal dialysis (CAPD). Perit Dial Int. Peritoneal Dialysis International 1989;9:115-119

23 Topley N. Membrane longevity in peritoneal dialysis: impact of infection and bio-incompatible solutions. Adv Ren Replace Ther 1998; 5(3):179-184

24 Topley N, Alobaidi HM, Davies M, Coles GA, Williams JD, Lloyd D. The effect of dialysate on peritoneal phagocyte oxidative metabolism. Kidney Int 1988;34(3):404-411

25 Davies SJ, Phillips L, Naish PF, Russell GI. Peritoneal glucose exposure and changes in membrane solute transport with time on Peritoneal Dialysis. J Am Soc Nephrol 2001;12(5):1046-1051

26 Davies SJ. Longitudinal relationship between solute transport and ultrafiltration capacity in peritoneal dialysis patients. Kidney Int 2004;66: 2437-2445

27 Williams JD, Craig KJ, Topley N, et al. Morphologic changes in the peritoneal membrane of patients with renal disease. J Am Soc Nephrol 2002;13(2):470-479

28 Rigby RJ, Hawley CM. Sclerosing peritonitis: the experience in Australia. Nephrol Dial Transplant 1998;13(1):154-159 
29 Lee HY, Kim BS, Choi HY, et al. Sclerosing encapsulating peritonitis as a complication of long-term continuous ambulatory peritoneal dialysis in Korea. Nephrology (Carlton) 2003;8(Suppl):S33-39

30 Rippe B, Wieslander A, Musi B. Long-term results with low glucose degradation product content in peritoneal dialysis fluids. Contrib Nephrol 2003(140):47-55

- 31 Jones S, Holmes CJ, Krediet RT, et al. Bicarbonate/lactate-based peritoneal dialysis solution increases cancer antigen 125 and decreases hyaluronic acid levels. Kidney Int 2001;59(4):1529-1538

- 32 Jones S, Holmes CJ, Mackenzie RK, et al. Continuous dialysis with bicarbonate/lactate-buffered peritoneal dialysis fluids results in a long-term improvement in ex vivo peritoneal macrophage function. J Am Soc Nephrol 2002;13(Suppl 1):S97-103

33 Williams JD, Topley N, Craig KJ, et al. The Euro-Balance Trial: the effect of a new biocompatible peritoneal dialysis fluid (balance) on the peritoneal membrane. Kidney Int 2004;66(1):408-418

34 Marshall J, Jennings P, Scott A, Fluck RJ, McIntyre CW. Glycemic control in diabetic CAPD patients assessed by continuous glucose monitoring system (CGMS). Kidney Int 2003;64(4):1480-1486

35 Lee HY, Park HC, Seo BJ, et al. Superior patient survival for continuous ambulatory peritoneal dialysis patients treated with a peritoneal dialysis fluid with neutral $\mathrm{pH}$ and low glucose degradation product concentration (Balance). Perit Dial Int 2005;25(3):248-255

36 Han SH, Ahn SV, Yun JY, Tranaeus A, Han D-S. Mortality and technique failure in peritoneal dialysis using advanced peritoneal dialysis solutions. AM J Kidney Dis 2009;54:711-720

37 Ahmad S, Sehmi JS, Ahmad-Zakhi KH, Clemenger M, Levy JB, Brown EA. Impact of new dialysis solutions on peritonitis rates. Kidney Int 2006;70:S63-66

- 38 Montenegro J, Saracho R, Gallardo I, Martínez I, Muñoz R, Quintanilla $\mathrm{N}$. Use of pure bicarbonate-buffered peritoneal dialysis fluid reduces the incidence of CAPD peritonitis. Nephrol Dial Transplant 2007;22:17031708

- 39 Kim S, Oh J, Kim S, Chung W, Ahn C, Kim SG, Oh K-H. Benefits of biocompatible PD fluid for preservation of residual renal function in incident CAPD patients: a 1-year study. Nephrol Dial Transplant 2009;24:2899-2908

40 Davies SJ. Preserving residual renal function in peritoneal dialysis: volume or biocompatibility? Nephrol Dial Transplant 2009;24:26202622 
2. Peritoneal Dialysis (PD) (Guidelines PD 2.1-2.4)

\section{Guideline 2.1 - PD: Preparation for Peritoneal Dialysis}

We recommend that all patients should, where possible, be adequately prepared for renal replacement therapy and this should include receiving information and education about PD treatment, delivered by an experienced member of the MDT. Patients commencing RRT in an unplanned fashion for whatever reason should receive this information once appropriate. (1C) Fast track education and urgent PD catheter insertion with acute start of PD should be available, and be offered to suitable patients urgently starting on RRT who wish to avoid temporary haemodialysis. (1C)

\section{Audit Measures}

Audit of care pathway for dialysis preparation to include information given (including proportion of patients offered $\mathrm{PD}$ ), when and who delivers it.

Audit of information on modality options provided to patients presenting who urgently require RRT, and both initial and subsequent modality of RRT selected by these patients.

\section{Rationale}

The arguments and rationale for this guideline relate to the National Service Framework for Renal Services, Part 1. The reader is referred to standard 2, Preparation and Choice pp. 21-23. The vast majority of patients commencing dialysis are medically suitable to receive PD if they select it. Some commonly perceived medical 'contraindications' to PD are overstated. The majority of patients with a previous history of major abdominal surgery may successfully be treated with PD [1]. It is also unusual to be unable to achieve target small solute clearances in the majority of larger patients (with the availability of APD, even when anuric).

When patients present needing a prompt, unplanned start to renal replacement therapy, rapid insertion of a PD catheter with acute start of PD, along with fast track education regarding dialysis modalities, may allow a proportion to commence directly on $\mathrm{PD}$, avoiding temporary vascular access and urgent haemodialysis [2, 3]. Such patients who initially receive acute start of haemodialysis should receive follow up education regarding RRToptions.

\section{Guideline 2.2 - PD: Preparation for Peritoneal Dialysis}

We recommend that, where possible, timing of $\mathrm{PD}$ catheter insertion should be planned to accommodate patient convenience, and commencement of training between 10 days and 6 weeks before RRT is essential to enable correction of early catheter-related problems without the need for temporary haemodialysis. (1C)

\section{Audit Measure}

Audit of care pathway for catheter insertion to include timeliness and need for temporary haemodialysis

\section{Rationale}

The arguments and rationale for this guideline relate to the National Service Framework for Renal Services, Part 1. The reader is referred to standard 3, Elective Dialysis Access Surgery, pp. 24-26. The Moncrief catheter is buried subcutaneously and is designed to be left in this position, where it can remain for many months, until required [4].

\section{Guideline 2.3 - PD: Preparation for Peritoneal Dialysis}

We recommend that $\mathrm{PD}$ catheter insertion practice should be managed according to the Renal Association Peritoneal Access Guidelines.

\section{Guideline 2.4 - PD: Preparation for Peritoneal Dialysis}

We recommend that peri-operative catheter care and catheter complications (leaks, hernias, obstruction) should be managed according to the International Society of Peritoneal Dialysis guidelines available at www.ispd.org

\section{Audit Measure}

Catheter complications and their resolution

\section{Rationale for Guidelines 2.3 and 2.4}

The Renal Association recommendations for PD catheter insertion have been adopted by the International Society of Peritoneal Dialysis and published [5]. For management of the catheter in the peri-operative period, for catheter related problems including leak (internal and external), poor flow, obstruction and hernias the guidelines developed by the International Society of Peritoneal Dialysis should be used, www.ispd. org $[6,7]$. Catheter problems due to increased intraperitoneal pressure, especially leaks, hernias and prolapse are an important medical indication for the use of APD either temporarily or permanently; poor flow or catheter related flow pain should be treated with tidal APD. In the 
majority of cases where surgical repair for mechanical complications is required (e.g. catheter replacement, hernia repair) it is possible to avoid the need to temporary haemodialysis. In many PD patients, remaining residual renal function may permit an adequate period post-surgery before dialysis needs to be recommenced. Where PD does need to start soon after surgery, in many cases this may be safely achieved by initial use of APD with small volume exchanges and avoiding a day dwell in ambulant patients [8].

\section{References}

1 Chen S-Y, Chen T-W, Lin S-H, Chen C-J, Yu Y-C, Kin C-H. Does previous abdominal surgery increase postoperative complication rates in continuous ambulatory peritoneal dialysis? Perit Dial Int 2007;27:557-559

2 Povlsen JV, Ivarsen P. How to start late referred ESRD patient urgently on chronic APD Nephrol Dial Transplant 2006;21(Suppl 2): ii56-ii59

$\checkmark 3$ Lobbedez T, Lecouf A, Ficheux M, Henri P, de Ligny BH, Ryckelynck J-P. Is rapid initiation of peritoneal dialysis feasible in unplanned dialysis patients? A single-centre experience. Nephrol Dial Transplant 2008;23: 3290-3294

4 Gokal R, Alexander S, Ash S, et al. Peritoneal catheters and exit-site practices toward optimum peritoneal access: 1998 update. (Official report from the International Society for Peritoneal Dialysis). Perit Dial Int 1998;18(1):11-33
5 Figueiredo A, Goh B, Jenkins S, Johnson DW, Mactier R, Ramalakshmi S, Shrestha B, Struijk D, Wilkie M. Clinical practice guidelines for peritoneal access. Perit Dial Int 2010;30:424-429

6 Flanigan M, Gokal R. Peritoneal catheters and exit-site practices toward optimum peritoneal access: a review of current developments. Perit Dial Int 2005;25(2):132-139

7 Crabtree JH. Rescue and salvage procedures for mechanical and infectious complications of peritoneal dialysis. Int J Artif Organs 2006; 29(1):67-84

8 Shah H, Chu M, Bargman JM. Perioperative management of peritoneal dialysis patients undergoing hernia surgery without use of interim hemodialysis. Perit Dial Int 2006;26:684-687 


\section{Peritoneal Dialysis (PD) (Guidelines PD 3.1-3.3)}

\section{Guideline 3.1 - PD: Solute Clearance}

We recommend that both residual urine and peritoneal dialysis components of small solute clearance should be measured at least six monthly or more frequently if dependant on residual renal function to achieve clearance targets or if clinically or biochemically indicated. Both urea and/or creatinine clearances can be used to monitor dialysis adequacy and should be interpreted within the limits of the methods. (1C)

\section{Audit Measure}

Frequency of solute clearance (residual and peritoneal) estimation

\section{Rationale}

Small solute clearance is one of the measurements of adequate dialysis treatment. Salt and water removal and acid-base balance are considered in sections 4 and 6 respectively. There are two issues in measuring small solute clearance that need to be taken into consideration.

First, the relationship to clinical outcomes of residual renal versus peritoneal small solute clearance is quantitatively different. Observational studies have shown that preserved renal clearance, in fact just urine volume, is associated with improved survival, independent of other known factors such as age and comorbidity [1, 2]. Randomised controlled trials designed to replace this residual renal function with peritoneal clearance did not show a proportional survival benefit $[3,4]$. The recommendation to measure solute clearance sixmonthly is driven primarily by the residual renal function component; indeed if dialysis dose has not been changed the peritoneal component will not be different and it would be acceptable just to measure the residual renal function. Indeed RRF can fall rapidly in some patients, certainly within a few weeks. If there are clinical concerns (e.g. if changes in symptoms, blood biochemistry, reported fall in urine output or after potential insults to residual renal function), or if achievement of solute clearance target is dependant on residual renal function, this should be undertaken more frequently.

Second, there are two potential surrogate solutes, urea and creatinine, that can be used to measure solute clearance in PD patients. There is no clear evidence as to which is the more useful clinically, and both have their problems. Current advice, therefore, is that either one or both can be used, ensuring that minimal clearances are achieved for at least one, but clinicians should be aware of their differing limitations. Urea clearances are limited by the difficulty in PD patients of estimating $\mathrm{V}$ accurately, whilst peritoneal creatinine clearances are affected by membrane transport characteristics (see Appendix).

\section{Guideline 3.2.1 - PD: Solute Clearance}

We recommend that a combined urinary and peritoneal Kt $/ \mathrm{V}_{\text {urea }}$ of $\geqslant 1.7 /$ week or a creatinine clearance of $\geqslant 50 \mathrm{~L} /$ week $/ 1.73 \mathrm{~m}^{2}$ should be considered as minimal treatment doses. (1A)

\section{Guideline 3.2.2 - PD: Solute Clearance}

We recommend that the dose should be increased in patients experiencing uraemic symptoms. (1B)

\section{Guideline 3.3 - PD: Solute Clearance}

We recommend that a continuous 24 hour PD regime is preferred to an intermittent regime. (1B)

\section{Audit Measure}

Cumulative frequency curves for the total solute clearance

\section{Rationale for Guidelines 3.2 and 3.3}

Two randomised controlled trials (ADEMEX and Hong Kong) have evaluated the impact of peritoneal solute clearances on clinical endpoints [3, 4]. Neither found that an increase of peritoneal $\mathrm{Kt} / \mathrm{V}_{\text {urea }}>1.7$ was associated with an improvement in survival. Only one of these studies (ADEMEX) measured creatinine clearance, which was the solute used to make decisions in this case; patients in the control group achieved an average peritoneal creatinine clearance of $46 \mathrm{~L} / 1.73 \mathrm{~m}^{2} /$ week and a total (urine plus renal) of $54 \mathrm{~L} / 1.73 \mathrm{~m}^{2} /$ week. In setting a recommendation for minimal peritoneal clearances, to be achieved in anuric patients, the previous Renal Association guideline of Kt/V $>1.7$ and creatinine clearance $>50 \mathrm{~L} / 1.73 \mathrm{~m}^{2} /$ week is supported by both the randomised and observational data. In the Hong Kong study, patients randomised to a $\mathrm{Kt} / \mathrm{V}<1.7$, whilst their mortality was not significantly worse they had a significantly higher drop out rate, more clinical complications and worse anaemia. One observational longitudinal study demonstrated that patients develop malnutrition once the Kt/V falls below 1.7 with a three-fold increase in the death rate [5]. The NECOSAD study found that a creatinine clearance of $<40 \mathrm{~L} /$ week or a $\mathrm{Kt} / \mathrm{V}$ urea $<1.5$ was associated with increased mortality in anuric patients [6]. 
The vast majority of PD patients will be able to reach these clearance targets, especially if APD is employed [7]. These guidelines must however be viewed as recommendations for minimal overall clearance. In patients with residual renal function this renal clearance can be subtracted from the peritoneal clearance with confidence that the value of equivalent renal clearances is greater. Equally, in a patient achieving these clearances but experiencing uraemic symptoms, including reduced appetite or nutritional decline, or failing to achieve adequate acid base balance (see section 6) then the dialysis dose should be increased. Drop out due to uraemia or death associated with hyperkalaemia and acidosis was significantly more common in the control patients in the ADEMEX study [3]. In patients with borderline clearances, who fail to achieve these clearance targets, other aspects of patient wellbeing, long-term prognosis from other comorbidity and patient perspective should be considered in deciding whether switch of modality to haemodialysis is appropriate. It is important to note that spuriously low Kt/V urea may arise due to overestimation of $\mathrm{V}$ in patients with significant obesity (see Appendix).
ADEMEX randomised patients between a 'standard' CAPD regime of $4 \times 2$ litre exchanges (rather than a specific clearance value) vs enhanced prescription to obtain specified clearance targets [3]. Thus this study should not be used to justify routine reduction of dialysis prescription down to minimum clearance targets. The large ANZDATA observational study suggested a lower survival with low peritoneal $\mathrm{Kt} / \mathrm{V}$ [8]. One possible interpretation of the data is that low peritoneal clearances were linked to reduced dialysis prescription in patients with good residual renal function.

Also, there is a discrepancy between clearance of small solutes and larger molecules, which are more dependent on time of contact of dialysate with the peritoneal membrane than dialysate volume [9]. Thus continuous regimes are preferred to those with 'dry' periods (e.g. NIPD), particularly in anuric patients, even if small solute clearance targets can be achieved without continuous therapy in the patient. An exception to this is in the situation where a patient still has a large residual renal function.

\section{References}

1 Churchill DN, Taylor DW, Keshaviah PR. Adequacy of dialysis and nutrition in continuous peritoneal dialysis: association with clinical outcome. J Am Soc Nephrol 1996;7:198-207

-2 Bargman JM, Thorpe KE, Churchill DN. Relative contribution of residual renal function and peritoneal clearance to adequacy of dialysis: a reanalysis of the CANUSA study. J Am Soc Nephrol 2001;12(10):2158-2162

- 3 Paniagua R, Amato D, Vonesh E, et al. Effects of Increased Peritoneal Clearances on Mortality Rates in Peritoneal Dialysis: ADEMEX, a Prospective, Randomised, Controlled Trial. J Am Soc Nephrol 2002; 13(5):1307-1320

4 Lo WK, Ho YW, Li CS, et al. Effect of Kt/V on survival and clinical outcome in CAPD patients in a randomised prospective study. Kidney Int 2003;64(2):649-656

5 Davies SJ, Phillips L, Russell L, Naish PF, Russell GI. An analysis of the effects of increasing delivered dialysis treatment to malnourished peritoneal dialysis patients. Kidney Int 2000;57(4):1743-1754
6 Jansen MA, Termorshuizen F, Korevaar JC, Dekker FW, Boeschoten E, Krediet RT. Predictors of survival in anuric peritoneal dialysis patients. Kidney Int 2005;68(3):1199-1205

7 Brown EA, Davies SJ, Heimburger O, et al. Adequacy targets can be met in anuric patients by automated peritoneal dialysis: baseline data from EAPOS. Perit Dial Int 2001;21(Suppl 3):S133-137

8 Rumpsfeld M, McDonald SP, Johnson DW. Peritoneal small solute clearance is non-linearly related to patient survival in the Australian and New Zealand peritoneal dialysis patient populations. Perit Dial Int 2009;29:637-646

9 Kim DJ, Do JH, Huh WS, Kim YG, Oh HY. Dissociation between clearances of small and middle molecules in incremental peritoneal dialysis. Perit Dial Int 2001;21:462-466 


\section{Peritoneal Dialysis (PD) (Guidelines PD 4.1-4.5)}

\section{Guideline 4.1 - PD: Ultrafiltration and Fluid Management}

We recommend that peritoneal membrane function should be monitored regularly (6 weeks after commencing treatment and at least annually or when clinically indicated) using a peritoneal equilibration test (PET) or equivalent. Daily urine and peritoneal ultrafiltration volumes, with appropriate correction for overfill, should be monitored at least six-monthly. (1C)

\section{Audit Measure}

Frequency of measurement of membrane function, residual urine and peritoneal ultrafiltration volume

\section{Rationale}

Assessment of membrane function, specifically solute transport rate and ultrafiltration capacity) is fundamental to PD prescription. (See appendix for methodological description of membrane function tests). This is for the following reasons:

(a) There is considerable between-patient variability in both solute transport and ultrafiltration capacity that translates into real differences in achieved solute clearance and ultrafiltration unless they are accounted for in prescription practice [1-5].

(b) Membrane function is an independent predictor of patient survival; specifically high solute transport and low ultrafiltration capacity are associated with worse outcomes [6-10].

(c) Membrane function changes with time on therapy. There are early changes - usually during the first few weeks of treatment that can be avoided by performing tests 6 weeks after commencing PD. Later changes vary between patients but tend to be increasing solute transport and reduced ultrafiltration capacity; the rate of membrane change is accelerated in patients with earlier loss of residual renal function and greater requirement for hypertonic glucose solutions $[5,11,12]$.

The European Renal Best Practice advisory board have produced detailed recommendations for the methodology of evaluation of peritoneal membrane function in clinical practice, and for utilising the results in $\mathrm{PD}$ prescription [13].

Residual renal function, as discussed above, is one of the most important factors, along with age, comorbidity, nutritional status, plasma albumin and membrane function that predict survival in PD patients. Its rate of loss is variable and clinically significant changes can occur within 6 months. Total fluid removal is associated with patient survival, especially once anuric $[9,14-16]$.

\section{Guideline 4.2 - PD: Ultrafiltration and Fluid Management}

We recommend that dialysis regimens resulting in fluid reabsorption should be avoided. Patients with high or high average solute transport, at greatest risk of this problem, should be considered for APD and icodextrin. (1A)

\section{Audit Measure}

Identify patients with fluid reabsorption in long dwell

\section{Rationale}

Increased solute transport has been repeatedly shown to be associated with worse survival, especially in CAPD patients $[6-8,10]$. The explanation for this association is most likely to be because of its effect on ultrafiltration when this is achieved with an osmotic gradient (using glucose or amino-acid dialysis fluids). The reason is twofold: first, due to more rapid absorption of glucose, the osmotic gradient is lost earlier in the cycle resulting in reduced ultrafiltration capacity. Second, once the osmotic gradient is dissipated the rate of fluid reabsorption in high transport patients is more rapid. This will result in significant fluid absorption, contributing to a positive fluid balance, during the long exchange.

These problems associated with high transport can be avoided by using APD to shorten dwell length and by using icodextrin for the long exchange to prevent fluid reabsorption. Several randomised controlled trials have shown that icodextrin can achieve sustained ultrafiltration in the long dwell [17-21] and that this translates into a reduction in extracellular fluid volume $[22,23]$. Observational studies indicate that high solute transport is not associated with increased mortality or technique failure in APD patients, especially when there is also a high use of icodextrin $[8,9,24]$. Results from the ANZDATA Registry show that in high transport patients, treatment with APD was associated with a superior patient survival compared with CAPD [25]. Survival in low transport patients in contrast was lower with APD.

\section{Guideline 4.3 - PD: Ultrafiltration and Fluid Management}

We recommend that dialysis regimens resulting in routine utilisation of hypertonic (3.86\%) glucose 
exchanges should be avoided. Where appropriate this should be achieved by using icodextrin or diuretics. (1B)

\section{Audit Measure}

Number of patients regularly requiring hypertonic (3.86\% glucose) exchanges to maintain fluid balance

\section{Rationale}

There is growing evidence that regular use of hypertonic glucose dialysis fluid (3.86\%), and where possible glucose $2.27 \%$, is to be avoided. It is associated with acceleration in the detrimental changes in membrane function that occur with time on treatment $[3,26]$, as well as several undesirable systemic effects including weight gain [19,27], poor diabetic control [28], delayed gastric emptying [29], hyperinsulinaemia and adverse haemodynamic effects [30]. In addition to patient education to avoid excessive salt and fluid intake, where possible the use of hypertonic glucose should be minimised by enhancing residual diureses with the use of diuretics (e.g. frusemide 250mg daily) [31]. Substituting icodextrin for glucose solutions during the long exchange will result in equivalent ultrafiltration whilst avoiding the systemic effects of the glucose load [19, $23,28,30]$. Observational evidence would suggest that icodextrin is associated with less functional deterioration in the membrane in APD patients [26].

\section{Guideline 4.4 - PD: Ultrafiltration and Fluid Management}

We recommend that treatment strategies that favour preservation of renal function should be adopted where possible. These include the use of $\mathrm{ACEi}, \mathrm{ARBs}$ and diuretics, and the avoidance of episodes of dehydration. (1B)

\section{Rationale}

This is the single most important parameter in PD patients, and also the one most likely to change with time. Clinically significant changes can occur within three months. Because secretion of creatinine by the kidney at low levels of function overestimates residual creatinine clearance, it is recommended to express this as the mean of the urea and creatinine clearances. Observational and randomised studies have shown that episodes of volume depletion, whether unintentional or in response to active fluid removal with the intent of changing blood pressure or fluid status, are associated with increased risk of loss in residual renal function $[15,22,23,32]$. Care should be taken not to volume deplete a PD patient too rapidly or excessively. The need to determine an appropriate target weight to avoid the cardiac complications of occult fluid overload, whilst avoiding loss of residual renal function due to excessive fluid removal is a major challenge in the management of the PD patient who has still has a significant residual urine output. The use of diuretics to maintain urine volume is not associated with a risk to renal clearances [31]. ACE inhibitors, (ramipril $5 \mathrm{mg}$ ) [33] and ARBs (valsartan) [34] have been shown in randomised studies to maintain residual diuresis.

\section{Guideline 4.5 - PD: Ultrafiltration and Fluid Management}

We recommend that anuric patients who consistently achieve a daily ultrafiltration of less than $750 \mathrm{ml}$ should be closely monitored and the benefits of modality switch considered. (1B)

\section{Audit Measure}

Identify patients with a total fluid removal $<750 \mathrm{ml}$ per day

\section{Rationale}

Observational studies have consistently shown that reduced peritoneal ultrafiltration is associated with worse survival rates; whilst this is seen in studies with or without residual urine [14], this effect is most marked in anuric patients $[9,15]$. In the only prospective study to have preset an ultrafiltration target $(750 \mathrm{ml} /$ day $)$, patients who remained below this had higher mortality after correcting for age, time on dialysis, comorbidity and nutritional status. It is likely this association is multifactorial, but failure to prescribe sufficient glucose or icodextrin and a lower ultrafiltration capacity of the membrane were factors in this study and should be considered $[9,35]$. The European guidelines have suggested a 1 litre minimal daily ultrafiltration target [36] but there is insufficient evidence to say that such a target must be met at this stage. It is possible that in some patients with low ultrafiltration, this is appropriate to their low fluid intake, and that in these cases decreased survival possibly results from poor nutrition rather than fluid excess, and that increasing ultrafiltration would simply result in dehydration with its adverse effects. Blood pressure, salt (and fluid) intake, nutritional and fluid status, and presence of any features of uraemia should be taken into account. Nevertheless patients with less than $750 \mathrm{ml}$ ultrafiltration once anuric should be very closely monitored and the potential benefits of modality switch considered. 


\section{References}

1 Twardowski ZJ, Nolph KD, Khanna R, et al. Peritoneal Equilibration Test. Perit Dial Bull 1987;7:138-147

2 Smit W, van Dijk P, Langedijk MJ, et al. Peritoneal function and assessment of reference values using a 3.86\% glucose solution. Perit Dial Int 2003;23(5):440-449

- 3 Smit W, Schouten N, van den Berg N, Langedijk MJ, Struijk DG, Krediet RT. Analysis of the prevalence and causes of ultrafiltration failure during long-term peritoneal dialysis: a cross-sectional study. Perit Dial Int 2004;24(6):562-570

4 Selgas R, Bajo MA, Cirugeda A, et al. Ultrafiltration and small solute transport at initiation of $\mathrm{PD}$ : questioning the paradigm of peritoneal function. Perit Dial Int 2005;25(1):68-76

5 Davies SJ. Longitudinal relationship between solute transport and ultrafiltration capacity in peritoneal dialysis patients. Kidney Int 2004;66: 2437-2445

-6 Davies SJ, Phillips L, Naish PF, Russell G. Quantifying comorbidity in Peritoneal Dialysis patients and its relationship to other predictors of survival. Nephrol Dial Transplant 2002;17(6):1085-1092

7 Churchill DN, Thorpe KE, Nolph KD, Keshaviah PR, Oreopoulos DG, Page D. Increased peritoneal membrane transport is associated with decreased patient and technique survival for continuous peritoneal dialysis patients. J Am Soc Nephrol 1998;9:1285-1292

8 Rumpsfeld M, McDonald SP, Johnson DW. Higher peritoneal transport status is associated with higher mortality and technique failure in the Australian and New Zealand peritoneal dialysis patient populations. J Am Soc Nephrol 2006;17(1):271-278. Epub 2005 Nov 23

$\checkmark 9$ Brown EA, Davies SJ, Rutherford P, et al. Survival of Functionally Anuric Patients on Automated Peritoneal Dialysis: The European APD Outcome Study. J Am Soc Nephrol 2003;14(11):2948-2957

10 Brimble KS, Walker M, Margetts PJ, Kundhal KK, Rabbat CG. Metaanalysis: peritoneal membrane transport, mortality, and technique failure in peritoneal dialysis. J Am Soc Nephrol 2006;17(9):25912598. Epub 006 Aug 2

-11 Heimburger O, Wang T, Lindholm B. Alterations in water and solute transport with time on peritoneal dialysis. Perit Dial Int 1999; 19(Suppl 2):S83-90

12 del Peso G, Fernandez-Reyes MJ, Hevia C, et al. Factors influencing peritoneal transport parameters during the first year on peritoneal dialysis: peritonitis is the main factor. Nephrol Dial Transplant 2005; 20(6):1201-6

13 Van Biesen W, Heimburger O, Krediet R, Rippe B, La Milia V, Covic A, Vanholder R, for the ERBP working group on peritoneal dialysis. Evaluation of peritoneal membrane characteristics: a clinical advice for prescription management by the ERBP working group. Nephrol Dial Transplant 2010 (in press)

14 Ates K, Nergizoglu G, Keven K, et al. Effect of fluid and sodium removal on mortality in peritoneal dialysis patients. Kidney Int 2001;60(2):767776

15 Jansen MA, Termorshuizen F, Korevaar JC, Dekker FW, Boeschoten E, Krediet RT. Predictors of survival in anuric peritoneal dialysis patients. Kidney Int 2005;68(3):1199-1205

16 Paniagua R, Amato D, Mulais S, Vonesh E, Ramos A, Correa-Rotter R, Horl WH. Predictive value of brain natriuretic peptides in patients on peritoneal dialysis: results from the ADEMEX trial. Clin J Am Soc Nephrol 2008;3:407-415

17 Posthuma N, ter Wee PM, Verbrugh HA, et al. Icodextrin instead of glucose during the daytime dwell in CCPD increases ultrafiltration and 24-h dialysate creatinine clearance. Nephrol Dial Transplant 1997; 12(3):550-3
18 Plum J, Gentile S, Verger C, et al. Efficacy and safety of a 7.5\% icodextrin peritoneal dialysis solution in patients treated with automated peritoneal dialysis. Am J Kidney Dis 2002;39(4):862-71

19 Wolfson M, Piraino B, Hamburger RJ, Morton AR. A randomised controlled trial to evaluate the efficacy and safety of icodextrin in peritoneal dialysis. Am J Kidney Dis 2002;40(5):1055-1065

20 Ota K, Akiba T, Nakao T, et al. Peritoneal ultrafiltration and serum icodextrin concentration during dialysis with $7.5 \%$ icodextrin solution in Japanese patients. Perit Dial Int 2003;23(4):356-361

21 Finkelstein F, Healy H, Abu-Alfa A, et al. Superiority of icodextrin compared with $4.25+\mathrm{ACU}$ - dextrose for peritoneal ultrafiltration. J Am Soc Nephrol 2005;16(2):546-554

22 Konings CJ, Kooman JP, Schonck M, et al. Effect of icodextrin on volume status, blood pressure and echocardiographic parameters: A randomised study. Kidney Int 2003;63(4):1556-1563

23 Davies SJ, Woodrow G, Donovan K, et al. Icodextrin improves the fluid status of peritoneal dialysis patients: results of a double-blind randomised controlled trial. J Am Soc Nephrol 2003;14(9):2338-2344

24 Davies SJ. Mitigating peritoneal membrane characteristics in modern PD therapy. Kidney Int 2006;103:S76-83

25 Johnson DW, Hawley CM, McDonald SP, Brown FG, Rosman JB, Wiggins K, Bannister KM, Badve SV. Superior survival of high transporters treated with automated versus continuous ambulatory peritoneal dialysis. Nephrol Dial Transplant 2010 doi: 10.1093/ndt/gpf 780

26 Davies SJ, Brown EA, Frandsen NE, et al. Longitudinal membrane function in functionally anuric patients treated with APD: Data from EAPOS on the effects of glucose and icodextrin prescription. Kidney Int 2005;67(4):1609-1615

27 Fernstrom A, Hylander B, Moritz A, Jacobsson H, Rossner S. Increase of intra-abdominal fat in patients treated with continuous ambulatory peritoneal dialysis. Perit Dial Int 1998;18(2):166-171

28 Marshall J, Jennings P, Scott A, Fluck RJ, McIntyre CW. Glycemic control in diabetic CAPD patients assessed by continuous glucose monitoring system (CGMS). Kidney Int 2003;64(4):1480-1486

29 Van V, Schoonjans RS, Struijk DG, et al. Influence of dialysate on gastric emptying time in peritoneal dialysis patients. Perit Dial Int 2002; 22(1):32-38

30 Selby NM, Fonseca S, Hulme L, Fluck RJ, Taal MW, McIntyre CW. Hypertonic glucose-based peritoneal dialysate is associated with higher blood pressure and adverse haemodynamics as compared with icodextrin. Nephrol Dial Transplant 2005;20(9):1848-1853

31 Medcalf JF, Harris KP, Walls J. Role of diuretics in the preservation of residual renal function in patients on continuous ambulatory peritoneal dialysis. Kidney Int 2001;59(3):1128-33

32 Gunal AI, Duman S, Ozkahya M, et al. Strict volume control normalises hypertension in peritoneal dialysis patients. Am J Kidney Dis 2001; 37(3):588-593

33 Li PK, Chow KM, Wong TY, Leung CB, Szeto CC. Effects of an angiotensin-converting enzyme inhibitor on residual renal function in patients receiving peritoneal dialysis. A randomised, controlled study. Ann Intern Med 2003;139(2):105-112

- 34 Suzuki H, Kanno Y, Sugahara S, Okada H, Nakamoto H. Effects of an angiotensin II receptor blocker, valsartan, on residual renal function in patients on CAPD. Am J Kidney Dis 2004;43(6):1056-1064

35 Davies SJ, Brown E, Riegel W, et al. What is the link between poor ultrafiltration and increased mortality in anuric APD patients? Analysis of data from EAPOS. Perit Dial Int 2006;26(4):458-465

36 Dombros N, Dratwa M, Feriani M, et al. European best practice guidelines for peritoneal dialysis. 7 Adequacy of peritoneal dialysis. Nephrol Dial Transplant 2005;20(Suppl 9):ix24-ix27 


\section{Peritoneal Dialysis (PD) (Guidelines PD 5.1-5.2)}

\section{Guideline 5.1 - PD: Infectious Complications Guideline 5.1.1 - PD Infectious Complications: Prevention Strategies}

We recommend that $\mathrm{PD}$ units should undertake regular audit of their peritonitis and exit-site infection rates, including causative organism, treatment and outcomes. They should enter into active dialogue with their microbiology department and infection control team to develop optimal local treatment and prevention protocols. (1B)

\section{Guideline 5.1.2 - PD Infectious Complications: Prevention Strategies}

We recommend that flush-before-fill dialysis delivery systems should be used. (1A)

\section{Guideline 5.1.3 - PD Infectious Complications: Prevention Strategies}

We recommend that patients should undergo regular revision of their technique (at least annually or more frequently if indicated, such as after an episode of PDrelated infection or a significant interruption to the patient performing $\mathrm{PD}$ ) and receive intensified training if this is below standard. (1C)

\section{Guideline 5.1.4 - PD Infectious Complications: Prevention Strategies}

We recommend that initial catheter insertion should be accompanied by antibiotic prophylaxis. (1B)

\section{Guideline 5.1.5 - PD Infectious Complications: Prevention Strategies}

We recommend that invasive procedures should be accompanied by antibiotic prophylaxis and emptying the abdomen of dialysis fluid for a period commensurate with the procedure. (1C)

\section{Guideline 5.1.6 - PD Infectious Complications: Prevention Strategies}

We recommend that topical antibiotic administration should be used to reduce the frequency of Staph. aureus and Gram negative exit-site infection and peritonitis. (1A)

\section{Audit Measures}

Routine annual audit of infection prevention strategies Routine annual audit of PD peritonitis rates (including proportion of culture negative cases)
Rationale for Guidelines 5.1.1-5.1.6

The rationale underpinning the guidelines in this section is laid out in a series of documents published by the International Society of Peritoneal Dialysis, available on their web-site: www.ispd.org

Prevention strategies: Both the ISPD 2005 guidelines [1] and the NSF Part 1 place increasing emphasis on prevention strategies. Regular audit is essential to this progress and the following standards should be considered as minimal:

1. Peritonitis rates of less than 1 episode per 18 months in adults and 12 months in children (see NSF part 1)

2. A primary cure rate of $\geqslant 80 \%$

3. A culture negative rate of $<20 \%$

Patient training to perform PD technique by experienced PD nurses trained to do this as part of a formalised training programme is essential in patients commencing PD [2]. Greater experience of nurses providing training is associated with greater time to initial episode of peritonitis [3]. It is recommended that review of patient $\mathrm{PD}$ technique is performed on a regular basis, at least annually, or more frequently if there is evidence of inadequate technique or development of PD-related infection, or a significant interruption in the performing PD e.g. after a significant period of hospitalisation). Approaches that have been shown to reduce infection rates in randomised studies include increased intensity of training, [4] use of flush before fill systems, [5] antibiotic prophylaxis to cover catheter insertion and prevention of exit-site infections [1]. Several studies have addressed the latter issue; following demonstration that the risk of Staph aureus exit site infection (the organism responsible in $90 \%$ of cases) is associated with pre-existing skin carriage, several randomised studies demonstrated that clinical exit-site infection and associated peritonitis could be reduced by either nasal or exit-site application of mupirocin. This has led to the practice of applying mupirocin to all patients $[6,7]$ and this approach should be discussed with the local microbiology and infection control team. A more recent study, comparing mupirocin with gentamicin cream, found that the latter prevented both Staph aureus and Pseudomonas exit-site infections and peritonitis episodes [8]. This approach should be strongly considered in patients with a known history of Pseudomonas infections; again the policy should be discussed and agreed with the local microbiology team. 


\section{Guideline 5.2 - PD Infectious Complications \\ Guideline 5.2.1 - PD Infectious Complications: \\ Treatment}

We recommend that exit site infection is suggested by pain, swelling, crusting, erythema and serous discharge; purulent discharge always indicates infection. Swabs should be taken for culture and initial empiric therapy should be with oral antibiotics that will cover $S$. aureus and $P$. aeruginosa. (1B)

\section{Guideline 5.2.2 - PD Infectious Complications: Treatment}

We recommend that methicillin resistant organisms (MRSA) will require systemic treatment (e.g. vancomycin) and will need to comply with local infection control policies. (1C)

\section{Guideline 5.2.3 - PD Infectious Complications: Treatment}

We recommend that initial treatment regimens for peritonitis should include cover for bacterial Gram positive and Gram negative organisms including Pseudomonas species until result of culture and antibiotic sensitivities are obtained. (1C)

\section{Audit Measure}

Routine annual audit of infection outcomes

\section{Rationale for Guidelines 5.2.1-5.2.3}

The International Society of Peritoneal Dialysis (ISPD) has developed a simple scoring system for exit site signs and symptoms which is easy to use and gives guidance on when to treat immediately rather than waiting for a swab result. Purulent discharge is an absolute indicator for antibiotic treatment [1].

The ISPD has become less dogmatic about the initial choice of antibiotic treatment for peritonitis, provided that gram positive and negative infections are covered [1]. It is recognised that patterns of resistance vary considerably and thus a local policy must be developed.

\section{References}

1 Piraino B, Bailie GR, Bernardini J, et al. Peritoneal dialysis-related infections recommendations: 2005 update. Perit Dial Int 2005;25(2):107-131

2 Bernadinini J, Price V, Figueiredo A. Peritoneal dialysis patient training, 2006 Perit Dial Int 2006;26:625-632

3 Chow KM, Szeto CC, Law MC, Fung JSF, Li PK-T. Influence of peritoneal dialysis training nurses' experience on peritonitis rates. Clin J Am Soc Nephrol 2007;2:647-652

4 Hall G, Bogan A, Dreis S, et al. New directions in peritoneal dialysis patient training. Nephrol Nurs J 2004;31(2):149-54, 59-63

$\checkmark 5$ MacLeod A, Grant A, Donaldson C, et al. Effectiveness and efficiency of methods of dialysis therapy for end-stage renal disease: systematic reviews. Health Technol Assess 1998;2(5):1-166
6 Bernardini J, Piraino B, Holley J, Johnston JR, Lutes R. A randomised trial of Staphylococcus aureus prophylaxis in peritoneal dialysis patients: mupirocin calcium ointment $2 \%$ applied to the exit site versus cyclic oral rifampin. Am J Kidney Dis 1996;27(5):695-700

7 Piraino B. Staphylococcus aureus infections in dialysis patients: focus on prevention. Asaio J 2000;46(6):S13-17

8 Bernardini J, Bender F, Florio T, et al. Randomised, double-blind trial of antibiotic exit site cream for prevention of exit site infection in peritoneal dialysis patients. J Am Soc Nephrol 2005;16(2):539-545. Epub 2004 Dec 29 


\section{Peritoneal Dialysis (PD) (Guidelines PD 6.1-6.4)}

\section{Guideline 6.1 - PD: Metabolic Factors}

We recommend that standard strategies to optimise diabetic control should be used; these should be complemented by dialysis prescription regimens that minimise glucose, including glucose free solutions (icodextrin and amino-acids), where possible. (1B)

\section{Rationale}

Glycaemic control can be made worse by glucose absorption across the peritoneal membrane. Dialysis regimens that incorporate less glucose and more glucose free (amino acid, icodextrin) solutions have been shown to improve glycaemic control $[1,2]$.

\section{Guideline 6.2 - PD: Metabolic Factors}

We recommend that plasma bicarbonate should be maintained within the normal range; this can be achieved in the vast majority of patients by adjusting the dialysis dose and/or dialysate buffer concentration. Occasionally bicarbonate buffered solutions will be required. (1B)

\section{Audit Measure}

Cumulative frequency curves of plasma bicarbonate

\section{Rationale}

Two randomised controlled trials have suggested that clinical outcomes, including gaining lean body mass and reduced hospital admissions are achieved if the plasma bicarbonate is kept within the upper half of the normal range. $[3,4]$ Generally this can be achieved by using dialysis fluids with a $40 \mathrm{mmol}$ buffer capacity (lactate or bicarbonate results in similar plasma bicarbonate levels [5]) and ensuring that the dialysis dose is adequate (see section 3(b), above) [6]. However, for solutions with a lower buffering capacity, when patients are switched from an all lactate $(35 \mathrm{mmol} / \mathrm{l})$ to a $25 \mathrm{mmol}$ bicarbonate: $10 \mathrm{mmol}$ lactate mix, there is a significant improvement in plasma bicarbonate ( 24.4 to $26.1 \mathrm{mmol} / \mathrm{l}$ ), such that a higher proportion of patients will fall within the normal range [7]. Whilst bicarbonate solutions may have a role in biocompatibility (see section 1(e), above), they are generally not required to achieve satisfactory acid-base balance. The main reason for using a $35 \mathrm{mmol}$ buffer capacity solution (25:10 bicarbonate:lactate mix) is to avoid excessive alkalinisation [8].

Control of acidosis is especially important in malnourished patients who may benefit from the glucose available in dialysis solutions as a calories source. Amino acid solutions were developed in an attempt to address protein calorie malnutrition and several randomised studies have been conducted. In using amino acid solutions it is essential to ensure that acidosis does not develop and to use the solution at the same time as there is a significant intake of carbohydrate [9]. Despite demonstration that amino acids delivered in dialysis fluids are incorporated into tissue protein, the randomised trials have failed to show benefit in terms of hard clinical endpoints $[10,11]$.

\section{Guideline 6.3 - PD: Metabolic Factors}

We suggest that central obesity can worsen or develop in some PD patients. The risk of this problem, and associated metabolic complications, notably increased atherogenicity of lipid profiles and insulin resistance, can be reduced by avoiding excessive glucose prescription and using icodextrin. $(2 \mathrm{C})$

\section{Rationale}

Weight gain, or regain, is common after starting peritoneal dialysis and this is associated with a worsening in the lipid profile [12]. Randomised studies comparing glucose $2.27 \%$ with icodextrin in the long exchange have shown that the latter prevents weight gain, which in body composition studies is at least in part fat weight $[13,14]$. Recommendations on how to treat dyslipidaemia are published by the ISPD and include the use of statins [15]. There is no currently available trial data on the benefit of statins in PD patients with a hard clinical endpoint; the 4D and AURORA studies did not include PD patients and there are good reasons for believing that the PD patient population may be different.

\section{Guideline 6.4 - PD: Metabolic Factors}

We recommend that awareness of the effects of Icodextrin on assays for estimation of amylase and glucose (using glucose dehydrogenase) should be disseminated to patients, relatives, laboratory and clinical staff. (1C)

\section{Audit Measure}

Processes in place to increase awareness of interference of assays by icodextrin metabolites

\section{Rationale}

Use of icodextrin is associated with circulating levels of metabolites that can interfere with laboratory assays for amylase (or actually suppress amylase activity) [1619] and for glucose when finger-prick tests that utilise 
glucose dehydrogenase as their substrate are employed (manufactured by Boehringer Mannheim) [20-23]. In the case of amylase, the measured level will be reduced by $90 \%$, leading to the potential failure in the diagnosis of pancreatitis. No adverse events have been reported, but clinicians should be aware of this possibility. If clinical concern remains then plasma lipase can be used. In the case of glucose measurements, the methods using glucose dehydrogenase will over-estimate blood glucose levels, leading to a failure to diagnose hypoglycaemia. This has been reported on several occasions in the literature and has contributed to at least one death. Typically these errors occur in places and circumstances in which staff not familiar with peritoneal dialysis work, for example emergency rooms and non-renal wards. A number of solutions to this problem are under active review (e.g. use of alarm bracelets) but it is also the responsibility of health-care professionals to ensure that clinical environments in which their patients using icodextrin may find themselves are notified of this issue on a routine basis.

\section{References}

1 Marshall J, Jennings P, Scott A, Fluck RJ, McIntyre CW. Glycemic control in diabetic CAPD patients assessed by continuous glucose monitoring system (CGMS). Kidney Int 2003;64(4):1480-1486

-2 Panigua R, Ventura M-de-J, Avila-Díaz M, Cisneros A, VicentéMartinez M, Furlong M-del-C, Garcia-Gonzalez Z, Villanueva D, Orihuela O, Prado-Uribe M-del-C, Alcantara G, Amato D. Icodextrin improves metabolic and fluid management in high and high-average transport diabetic patients. Perit Dial Int 2009;29: 422-432

3 Stein A, Moorhouse J, Iles-Smith H, et al. Role of an improvement in acid-base status and nutrition in CAPD patients. Kidney Int 1997;52(4):1089-1095

$\checkmark 4$ Szeto CC, Wong TY, Chow KM, Leung CB, Li PK. Oral sodium bicarbonate for the treatment of metabolic acidosis in peritoneal dialysis patients: a randomised placebo-control trial. J Am Soc Nephrol 2003; 14(8):2119-2126

5 Coles GA, Gokal R, Ogg C, et al. A randomised controlled trial of a bicarbonate- and a bicarbonate/lactate-containing dialysis solution in CAPD. Perit Dial Int 1997;17(1):48-51

6 Mujais S. Acid base profile in patients on PD. Kidney Int 2003;64(Suppl. 88): S26-36

$>7$ Otte K, Gonzalez MT, Bajo MA, et al. Clinical experience with a new bicarbonate $(25 \mathrm{mmol} / \mathrm{L}) /$ lactate $(10 \mathrm{mmol} / \mathrm{L})$ peritoneal dialysis solution. Perit Dial Int 2003;23(2):138-145

$\checkmark 8$ Dratwa M, Wilkie M, Ryckelynck JP, et al. Clinical experience with two physiologic bicarbonate/lactate peritoneal dialysis solutions in automated peritoneal dialysis. Kidney Int 2003;88:S105-113

$\checkmark 9$ Kopple JD, Bernard D, Messana J, et al. Treatment of malnourished CAPD patients with an amino acid based dialysate. Kidney Int 1995; 47(4):1148-1157

10 Li FK, Chan LY, Woo JC, et al. A 3-year, prospective, randomised, controlled study on amino acid dialysate in patients on CAPD. Am J Kidney Dis 2003;42(1):173-183

11 Jones M, Hagen T, Boyle CA, et al. Treatment of malnutrition with $1.1 \%$ amino acid peritoneal dialysis solution: results of a multicenter outpatient study. Am J Kidney Dis 1998;32(5):761-769

$>12$ Little J, Phillips L, Russell L, Griffiths A, Russell GI, Davies SJ. Longitudinal lipid profiles on CAPD: their relationship to weight gain, comorbidity, and dialysis factors. J Am Soc Nephrol 1998;9(10):1931-1939
13 Wolfson M, Piraino B, Hamburger RJ, Morton AR. A randomised controlled trial to evaluate the efficacy and safety of icodextrin in peritoneal dialysis. Am J Kidney Dis 2002;40(5):1055-1065

14 Davies SJ, Woodrow G, Donovan K, et al. Icodextrin improves the fluid status of peritoneal dialysis patients: results of a double-blind randomised controlled trial. J Am Soc Nephrol 2003;14(9):2338-2344

15 Fried L, Hutchison A, Stegmayr B, Prichard S, Bargman JM. Recommendations for the treatment of lipid disorders in patients on peritoneal dialysis. ISPD guidelines/recommendations. International Society for Peritoneal Dialysis. Perit Dial Int 1999;19(1):7-16

16 Schoenicke G, Grabensee B, Plum J. Dialysis with icodextrin interferes with measurement of serum alpha-amylase activity. Nephrol Dial Transplant 2002;17(11):1988-1992

17 Wang R, Leesch V, Turner P, Moberly JB, Martis L. Kinetic analysis of icodextrin interference with serum amylase assays. Adv Perit Dial 2002;18:96-99

18 Anderstam B, Garcia-Lopez E, Heimburger O, Lindholm B. Determination of alpha-amylase activity in serum and dialysate from patients using icodextrin-based peritoneal dialysis fluid. Perit Dial Int 2003; 23(2):146-150

19 Garcia-Lopez E, Anderstam B, Heimburger O, Amici G, Werynski A, Lindholm B. Determination of high and low molecular weight molecules of icodextrin in plasma and dialysate, using gel filtration chromatography, in peritoneal dialysis patients. Perit Dial Int 2005; 25(2):181-191

20 Wens R, Taminne M, Devriendt J, et al. A previously undescribed side effect of icodextrin: overestimation of glycemia by glucose analyser. Perit Dial Int 1998;18(6):603-609

21 Oyibo SO, Pritchard GM, McLay L, et al. Blood glucose overestimation in diabetic patients on continuous ambulatory peritoneal dialysis for end-stage renal disease. Diabet Med 2002;19(8):693-696

-22 Mehmet S, Quan G, Thomas S, Goldsmith D. Important causes of hypoglycaemia in patients with diabetes on peritoneal dialysis. Diabet Med 2001;18(8):679-682

23 Janssen W, Harff G, Caers M, Schellekens A. Positive interference of icodextrin metabolites in some enzymatic glucose methods. Clin Chem 1998;44(11):2379-2380 


\section{Peritoneal Dialysis (PD) (Guidelines PD 7.1)}

\section{Guideline 7.1 - PD: Encapsulating Peritoneal Sclerosis}

We recommend that the diagnosis and management of encapsulating peritoneal sclerosis (EPS), including consideration of surgical management of EPS, should follow the principles outlined in the UK Encapsulating Peritoneal Sclerosis Clinical Practice Guidelines.

\section{Rationale}

Diagnosis of and management of EPS, including consideration of surgical management of EPS, should follow the UK EPS Clinical Practice Guidelines [1].

\section{Guideline 7.2 - PD: Encapsulating Peritoneal Sclerosis}

We recommend that there is no optimal duration of peritoneal dialysis and decisions regarding the duration of therapy should be tailored to the individual patient, taking into account clinical and social factors and patients wishes, and should follow the principles outlined in the ISPD Length of Time on Peritoneal Dialysis and Encapsulating Peritoneal Sclerosis Position Paper.

\section{Rationale}

The risk of developing EPS is extremely low in the first 3 years of PD and low before 5 years of therapy. Whilst the risk increases with time, the majority of patients on longer term PD will not develop EPS. It is unknown what impact discontinuing PD after a certain period of time will have on the risk of developing EPS. Discontinuing PD may also have potentially major adverse negative medical and social effects in some patients. Thus routine discontinuation of PD after a fixed period of time cannot be recommended. The risks and benefits of continuing PD or dialysis modality change should be considered and discussed with the individual patient, as recommended in the ISPD Length of Time on Peritoneal Dialysis and Encapsulating Peritoneal Sclerosis Position Paper [2].

\section{References}

1 Woodrow G, Augustine T, Brown EA, Cowling M, El-Sherbini N, Hurst H, Williams PF, Williams R. UK Encapsulating Peritoneal Sclerosis Clinical Practice Guidelines, July 2007 at www.renal.org/pages/media/ download_gallery/EPSguideline240709.pdf
2 Length of time on peritoneal dialysis and encapsulating peritoneal sclerosis: position paper for ISPD. Brown EA, Van Biesen W, Finkelstein FO, Hurst H, Johnson DW, Kawanishi H, Pecoits-Filho R, Woodrow G. Perit Dial Int 2009;29:595-600

Saeed Ahmed, consultant nephrologist

Steven Bailey, PD patient

Linda Bisset, SpR in renal medicine Lindsay Chesterton, SpR in renal medicine Jeannette Denning, PD nursing sister Helen Hurst, PD nursing sister Colin Jones, consultant nephrologist Andrew Neil Pyrah, PD patient Martin Wilkie, consultant nephrologist 


\section{Appendix}

\section{Assessment of Membrane Function}

(a) A number of methods to assess peritoneal membrane have been developed, the most commonly used, supported by clinical observation being the Peritoneal Equilibration Test (PET). This test measures two aspects of membrane function, low molecular weight solute transport (expressed as the dialysate:plasma ratio of creatinine at four hours), and the ultrafiltration capacity of the membrane. In the PET as originally described, ultrafiltration capacity is the net volume of ultrafiltration achieved at four hours using a $2.27 \%$ glucose exchange $[1,2]$. In the simplified Standard Permeability Analysis (SPA) test, it is the net volume of ultrafiltration using a $3.86 \%$ exchange $[3,4]$.

(b) Using a standard PET, an ultrafiltration capacity of $<200 \mathrm{mls}$ (including overfill) is associated with a $50 \%$ risk of achieving $<1000 \mathrm{mls}$ ultrafiltration in anuric patients. Using a SPA test, an ultrafiltration capacity of $<400 \mathrm{mls}$ indicates ultrafiltration failure.

(c) The methods of performing PET and SPA tests are well described in the literature, The following points should be remembered in the interpretation of results:

- High concentrations of glucose interfere with many assays for creatinine. It is important to work with the local biochemists to ensure that the appropriate correction for measurement of creatinine in dialysate has been taken into account.

- Remember that dialysis bags are overfilled, mainly due to the additional fluid volume required to perform the 'flush before fill' procedure. Dialysis manufacturers are being encouraged to publish overfill volumes which differ significantly. The typical volume is 100 $200 \mathrm{ml}$. The value of $200 \mathrm{ml}$ UF capacity defining ultrafiltration failure quoted above includes the flush volume as this is easier for patients to perform (the alternative is weighing before and after flush which is time consuming and difficult).

- The patient should follow their usual dialysate regime, draining out as completely as possible before the test dwell. Large residual volume of dialysate will affect the results.

- Intra-patient variability of the ultrafiltration capacity $(\sim 20 \%)$ is greater than for the solute transport $(<10 \%)$. Results of the PET/SPA, in particular the ultrafiltration capacity, should always be interpreted in the light of additional exchanges performed during the same 24-48 hour period (usually collected to assess solute clearance - see below).

- The PET/SPA are not surrogates for measuring solute clearance.

(d) The PET or SPA should be seen as a regular screening test to monitor membrane function and in most cases will explain clinically evident. ultrafiltration problems. More detailed assessment of the membrane can be undertaken, in particular the double mini-PET. For further advice on this see the European Renal Best Practice Guidelines for assessing membrane function.

\section{Measurement of Solute Clearance}

In measuring solute clearance and planning changes to the dialysis regime, three clinical parameters are essential: Estimates of (1) patient size, (2) peritoneal solute transport and (3) RRF. In each case, the choice of surrogate 'toxin', urea or creatinine, interacts with each of these parameters in different ways. At present, there is no clear evidence from the literature that one surrogate is superior to another. Where possible, clinicians should measure both, attempt to reach at least one of the targets, and understand why there appears to be a discrepancy. A number of commercial computer programs exist that are designed to aid dialysis prescription. Whilst some have been validated, good practice dictates that a change in dialysis prescription is checked for efficacy by repeating clearance studies.

\section{(1) Patient Size}

In calculating urea clearances, patient size is expressed as an estimate of the total body water (volume of distribution of urea). It is recommended that the Watson formula is used for this [5]:

$$
\text { Males: } \begin{aligned}
\mathrm{V}= & 2.447-0.09156 \times \text { age }(\text { years })+0.1074 \\
& \times \text { height }(\mathrm{cm})+0.3362 \times \text { weight }(\mathrm{kg})
\end{aligned}
$$

Females: $\mathrm{V}=-2.097+0.1069 \times$ age $($ years $)$

$$
+0.2466 \text { weight }(\mathrm{kg})
$$

Anthropometric equations estimating TBW may produce results significantly different to gold standard dilution techniques (REF). This will impact on estimates of $\mathrm{Kt} / \mathrm{V}$ and is of relevance if borderline $\mathrm{Kt} / \mathrm{V}$ values are 
obtained $[6,7]$. Alternatively $58 \%$ of body weight $(\mathrm{kg})$ may be used; this is less precise, and will give lower values for $\mathrm{Kt} / \mathrm{V}$, especially in obese patients. Creatinine clearances should be corrected for body surface area, normalising to $1.73 \mathrm{~m}^{2}$.

\section{(2) Peritoneal Solute Transport}

Solute transport rates have an important influence on peritoneal creatinine clearance, but not on urea clearance. This means that it is easier to achieve creatinine clearance targets in high transport patients. It should be remembered, however, that these patients might have less satisfactory ultrafiltration. In designing optimum dialysis regimens, patients with low solute transport will require equally spaced medium length dwells, such as are achieved with CAPD and single extra night exchanges (e.g. $5 \times 2.5$ litre exchanges). Those with high transport are more like to achieve targets with short dwells (APD) plus polyglucose solutions (e.g. $4 \times 2.5$ litre exchanges overnight, $1 \times 2.5$ litre evening exchange and $1 \times 2.5$ litre daytime icodextrin).

\section{(3) Residual Renal Function (RRF)}

This is the single most important parameter in PD patients, and also the one most likely to change with time. Clinically significant changes can occur within three months. Because secretion of creatinine by the kidney at low levels of function overestimates residual creatinine clearance, it is recommended to express this as the mean of the urea and creatinine clearances.

\section{Estimating Total Ultrafiltration}

The total achieved ultrafiltration is best measured from the 24-hour dialysate collections used to calculate solute clearance. For APD patients this is simple as machines now calculate the ultrafiltration volumes precisely. Furthemore, many models store this information over several weeks so that an average value can be obtained. In CAPD patients it is important to remember that each bag is overfilled to achieve flush before fill; the total dialysate drain volume must be measured and sampled from to calculate solute clearance accurately, but the overfill must then be subtracted to calculate the net ultrafiltration. If this is not done then over a 24hour period the overestimate of ultrafiltration may be anything from 200 to $800 \mathrm{ml}$ depending on manufacturer $[8,9]$.

Peritoneal sodium losses are largely determined by convection and are thus proportional to the ultrafiltration volume. Typically 1 litre of ultrafiltration results in $100 \mathrm{mmol}$ of sodium loss in CAPD patients and $70-80 \mathrm{mmol}$ in APD patients.

\section{References}

1 Twardowski ZJ, Nolph KD, Khanna R, et al. Peritoneal Equilibration Test. Perit Dial Bull 1987;7:138-147

2 Davies SJ, Brown B, Bryan J, Russell GI. Clinical evaluation of the peritoneal equilibration test: a population-based study. Nephrol Dial Transplant 1993;8(1):64-70

3 Ho-dac-Pannekeet MM, Atasever B, Struijk DG, Krediet RT. Analysis of ultrafiltration failure in peritoneal dialysis patients by means of standard peritoneal permeability analysis. Perit Dial Int 1997;17(2):144-150

-4 Smit W, van Dijk P, Langedijk MJ, et al. Peritoneal function and assessment of reference values using a $3.86 \%$ glucose solution. Perit Dial Int 2003;23(5):440-449

5 Watson PE, Watson ID, Batt RD. Total body water volume for adult males and females estimated from simple anthropometric measurements. Am J Clin Nutr 1980;33:27-39
6 Woodrow G, Oldroyd B, Turney JH, Davies PSW, Day JME, Smith MA. Measurement of total body water and urea kinetic modelling in peritoneal dialysis. Clin Nephrol 1997;47: 52-57

7 Woodrow G, Oldroyd B, Wright A, Coward A, Truscott JG, Turney JH, Brownjohn AM, Smith MA. Comparison of anthropometric equations for estimation of total body water in peritoneal dialysis patients. Nephrol Dial Transplant 2003;18: 384-389

8 McCafferty K, Fan S. Are we underestimating the problem of ultrafiltration in peritoneal dialysis patients? Perit Dial Int 2006;26(3):349-352

9 La Milia V, Pozzoni P, Crepaldi C, Locatelli F. The overfill of bags for peritoneal dialysis as a cause of underestimation of ultrafiltration failure. Perit Dial Int 2006;26(4):503-505 